\title{
Article \\ Stress and Pressure Pulsation Analysis of Low Temperature Compressor Piping System in LNG Vaporizing Station
}

\author{
Baoqing Wang ${ }^{1}$, Zhi Zhang ${ }^{2, *}$, Kun Huang ${ }^{2}$, Yaotong Zhang ${ }^{1}$, Zhenwu Zhang ${ }^{3}$, Hui Gao ${ }^{1}$ and Lingdi Fu ${ }^{4}$ \\ 1 Sinopec Tianjin LNG Co., Ltd., Tianjin 300457, China; baoqingwang@vip.sina.com (B.W.); \\ zhangyaotong.trqi@sinopec.com (Y.Z.); gaohui.trqi@sinopec.com (H.G.) \\ 2 Petroleum Engineering School, Southwest Petroleum University, Chengdu 610500, China; \\ hkswpu@swpu.edu.cn \\ 3 Anhui Province Natural Gas Development Co., Ltd., Hefei 230051, China; zhangzhenwu71@163.com \\ 4 Environment and Technology Supervision Research Institute, PetroChina Southwest Oil \& Gasfield Company, \\ Chengdu 610041, China; cyrilf@126.com \\ * Correspondence: 202121000936@stu.swpu.edu.cn
}

Citation: Wang, B.; Zhang, Z.; Huang, K.; Zhang, Y.; Zhang, Z.; Gao, H.; Fu,

L. Stress and Pressure Pulsation Analysis of Low Temperature Compressor Piping System in LNG Vaporizing Station. Energies 2022, 15, 1874. https://doi.org/10.3390/ en15051874

Academic Editor: Luiz C. Wrobel

Received: 24 December 2021 Accepted: 28 February 2022 Published: 3 March 2022

Publisher's Note: MDPI stays neutral with regard to jurisdictional claims in published maps and institutional affiliations.

Copyright: (C) 2022 by the authors. Licensee MDPI, Basel, Switzerland. This article is an open access article distributed under the terms and conditions of the Creative Commons Attribution (CC BY) license (https:// creativecommons.org/licenses/by/ $4.0 /$ )

\begin{abstract}
LNG (Liquefied Natural Gas) vaporizing stations are usually built in the cities and towns, and the BOG (Boiled Off Gas) pressurizing system is a very important element. In the pressurizing system, the severe vibration of the low-temperature reciprocating compressor may lead to a failure of the pipeline system and the equipment. Therefore, this paper analyzes the stress and pressure pulsation of the BOG compressor piping system in the LNG vaporizing station. The beam model was used to establish the pipe model. The static, harmonic and modal analysis were carried out based on the plane-wave theory and the pressure-fluctuation theory, and the influence factors of support spacing, the settlement of the fulcrum foundation, pipe pressure and elbow angle were analyzed. The main conclusions are as follows: (1) the unbalanced excited force caused by pressure pulsation greatly affects the stress of the exhaust pipe and compressor outlet pipe, and has less influence on the stress of the suction pipe and compressor inlet pipe; (2) although unbalanced excited force is generated in the elbow, it also has an impact on the straight pipe stress; (3) adding an expansion joint to the pipe of the BOG compressor can effectively reduce the stress of the pipe its the displacement, and can increase the flexibility of the pipe.
\end{abstract}

Keywords: LNG vaporizing station; low temperature compressor; piping system; stress analysis; modal analysis; pressure pulsation

\section{Introduction}

LNG (Liquefied Natural Gas) is a type of cryogenic liquid that cools gaseous natural gas to $-162{ }^{\circ} \mathrm{C}$ under atmospheric pressure. The LNG pipeline may experience destructive stress because of cold shrinkage, and there is a great safety hazard in the process of operation. Especially in the LNG vaporizing station with BOG (Boiled Off Gas) compression process, the operation of the compressor causes pipe vibration and increase the stress of the pipe [1-5]. If the equipment or pipe ruptures, the LNG will leak and then rapidly volatilize and disperse. It can easily cause fires, explosions and other accidents, causing huge economic losses and casualties. Therefore, according to the regulation of GB/T 20801 "Pressure piping code Industrial piping Part 1: General" [6], a pipe-stress analysis should be carried out for pipes running at temperatures not less than $400{ }^{\circ} \mathrm{C}$ or not greater than $-70{ }^{\circ} \mathrm{C}$.

Chilton and Handley [7] discussed the installation position of two kinds of buffer (single-volume buffer and filter buffer) in the piping system. It was concluded that the control effect of the filter buffer on pressure pulsation is better in cases with the same volume. Sun Siying et al. [8] studied the installation position of the buffer, and found that the closer the buffer to the cylinder, the more obvious the effect of vibration elimination. 
Josef and Zhang Heli [9] designed an attenuator with a perforated tube, and proved that it could effectively attenuate the pulsation of the air flow. Shin et al. [10,11] carried out a theoretical analysis and experimental verification on the problem of attenuatorreducing pressure pulsation. The device is equivalent to the spring damping system, which can effectively control the pressure pulsation. Chen Lingli et al. [12,13] put forward a mathematical model for the optimization of the supporting stiffness of the piping structure of the compressor, and deduced the sensitivity analysis formula of the steady-state response amplitude with design variables under the exciting force. Cheng Mugen [14] analyzed the vibration causes of the inlet pipe of the water-injection pump, and put forward damping measures such as adding the accumulator and reducing the number of elbows. Xing Keli et al. [15] analyzed the conventional parallel capsule accumulator and a new type of tandem bladder accumulator, and discussed the effect of the installation position of the accumulator on the pressure-pulsation attenuation of the pump. Zhang Hongjuan [16] analyzed the vibration causes of the reciprocating pump pipe and proposed the addition of an air chamber to reduce the pressure pulsation. Xie Poan [17] used the transfer matrix method to establish the acoustic model of the accumulator, analyzed the attenuation effect of accumulator on the fluid pulsation in the pipeline, and verified it by experiment. Wang Qiang [18] put forward a structure for a pipeline vibration elimination device, which can reduce the vibration of the pipe and attenuate the pressure pulsation of the fluid. Xue Weifei [19] used the ANSYS software to analyze the vibration of the reciprocating compressor outlet pipe and to reduce the vibration by reforming the layout of the pipe. Xiao Gaomian [20] calculated the pressure pulsation of a complex piping system based on plane-wave theory by using the stiffness matrix method, and made use of Matlab software to compile the calculation program of gas pulsation. Yu Chenglong et al. [21] analyzed vibration and vibration-reduction measures for the reciprocating compressor pipe, and put forward measures to increase the buffer tank, namely by reducing the diameter. Chen Haifeng [22] analyzed the vibration characteristics of reciprocating compressor piping by the method of acoustic and electric simulation. This method equates the pipe unit to the circuit, which is convenient and fast, but it can only calculate the frequency of the pipe. Sui Kai and Wang Jie [23] analyzed the pressure pulsation of the water supply pipeline. The expression of the pressure pulsation was derived by the separation of variables, and the expression of the exciting force was deduced. Lu Hongfang [24] analyzed the stress and vibration of the reciprocating pump piping system using CAESAR II software, and put forward the measure of stress reduction.

Su Peng et al. [25] studied the effect of thermal stress on the LNG pipeline. Liu Huafeng et al. [26] carried out the stress calculation for a company's LNG storage tank's cryogenic inlet pipeline, studied the stress concentration and the large displacement position of the pipeline, and studied the influence of the spring hanger on the stress of the piping system. Yu Guopeng et al. [27] conducted a stress analysis of LNG cryogenic pipelines, and analyzed the influence of wind load, earthquake load and other factors on pipe stress. Qiang Xu et al. [28,29] conducted research on two-phase flow regimes of a long-distance pipeline-riser system and found that differential pressure signals at different pipe positions can have a significant impact on the recognition rate. Se-Yun Hwang et al. [30] studied pipe stresses of piping system installed on LNG carriers under various conditions using CAESAR-II software based on beam elements and conducted an evaluation of analytical results of piping arrangement of LNG.

According to the literature survey, there are few studies on the vibration of low temperature pipes, and the stress analysis of the BOG compressor piping system has not been studied yet. Based on the theory of pressure pulsation, this paper calculates the unbalanced exciting force of the pipeline. The stress and a harmonic and modal analysis of pipelines are studied by CAESAR II software, the influence factors of stress are analyzed and the corresponding stress-reduction measures are presented. 


\section{Basic Theories}

The system only vibrates when the system is disturbed by the initial disturbance (external force or displacement), and it is easy to cause resonance when the natural frequency of pipeline is close to the excitation frequency. In the BOG compressor piping system, the effect of pressure pulsation on pipeline stress is primarily studied.

\subsection{Plan Wave Theory}

The plane-wave theory uses linear equation to simplify the initial equation, so the linear vibration theory can be used to directly facilitate the calculation. As shown in Figure 1, at moment $t$, the physical parameter pressure, velocity and density are $p, u$ and $\rho$, respectively. When the fluid is a one-dimensional flow, $p, u, \rho$ are all functions related to $x$ and $t$.

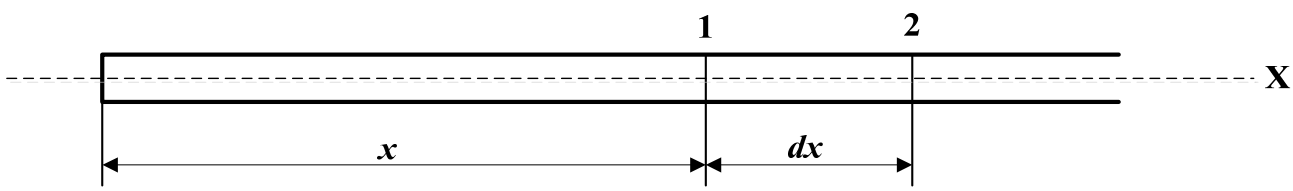

Figure 1. Fluid micromass of control volume in the pipe.

(1) Continuity equation

$$
\frac{\partial \rho}{\partial t}+u \frac{\partial \rho}{\partial x}+\rho \frac{\partial u}{\partial x}=0
$$

(2) Motion equation

$$
\frac{\partial u}{\partial t}+u \frac{\partial u}{\partial x}=-\frac{1}{\rho} \frac{\partial p}{\partial x}
$$

(3) Wave equation

$$
\frac{\partial p}{\partial t}+u \frac{\partial p}{\partial x}+\rho c^{2} \frac{\partial u}{\partial x}=0
$$

\subsection{Pressure Pulsation and Unbalanced Exciting Force}

Pressure pulsation refers to the maximum amplitude deviating from the average pressure $p$. Without the pressure data of the pipeline in the scene, it is difficult to adopt the shock-wave theory calculation. In order to be able to carry out the analysis more accurately, the calculation is made by the method of separation of variables.

The expression of pressure pulsation is as follows [23]:

$$
p_{\Delta}(x, t)=\left[\frac{-2 p}{n \pi}(\cos n \pi l-1) \cos \omega_{n} t+\frac{-2 u}{n^{2} \pi^{2} c l}(\cos n \pi l-1) \sin \omega_{n} t\right] \sin \frac{n \pi}{l} x
$$

where $p_{\Delta}(x, t)=$ pressure pulsation at $x$ position and $t$ moment, Pa; $n=$ order number; $c=$ sound velocity, $\mathrm{m} / \mathrm{s} ; l=$ total pipe length, $\mathrm{m} ; x=$ distance from the starting point, $\mathrm{m}$; $\omega_{n}=$ excitation circular frequency, $\mathrm{rad} / \mathrm{s} ; p=$ initial pressure, $\mathrm{Pa} ; u=$ initial velocity, $\mathrm{m} / \mathrm{s}$.

The pressure inhomogeneity is the symbol used to measure the pressure pulsation, and the pressure inhomogeneity can be calculated as:

$$
\delta=\frac{p_{\Delta \max }-p_{\Delta \min }}{p_{0}} \times 100 \%,
$$

where $p_{\Delta \max }=$ the maximum value of pressure pulsation; $p_{\Delta \min }=$ the minimum value of pressure pulsation; $p_{0}=$ the average pressure, $p_{0}=\frac{p_{\max }-p_{\min }}{2}$.

According to the requirements of API 618 "Reciprocating Compressors for Petroleum, Chemical, and Gas Industry Services" [31], the unfiltered gas pressure inhomogeneity at 
the cylinder flange of the compressor should be within the range of Equation (6), and if the calculated value is greater than $7 \%$, it should be taken as $7 \%$.

$$
\delta_{\mathrm{cf}}=3 R,
$$

where $\delta_{\mathrm{cf}}=$ allowable value of pressure inhomogeneity, $\% ; R=$ the ratio of the absolute pressure of the compressor outlet to the absolute pressure of the inlet.

In the BOG compressor piping system, the BOG gas becomes periodically excited by the compressor due to the reciprocating motion of the BOG compressor, creating a pressure pulsation. The pressure pulsation is transmitted through the BOG as a pressure wave. At different locations, the pressure pulsation reaches a peak at different times. The pressure pulsation produces the exciting force at the elbow, tee or other components, and the exciting force varies with time, which affects the stress of the pipes. As it shown in Figure 2, assuming that $d$ represents the inner diameter of the pipe, $\beta$ stands for the angle of elbow, the inlet and outlet pressures are $p$, and the resultant force of elbow can be calculated as:

$$
R=2 F_{1} \sin \left(\frac{\beta}{2}\right)=2 F_{2} \sin \left(\frac{\beta}{2}\right)=2\left(\frac{\pi d^{2} p}{4}\right) \sin \left(\frac{\beta}{2}\right)
$$

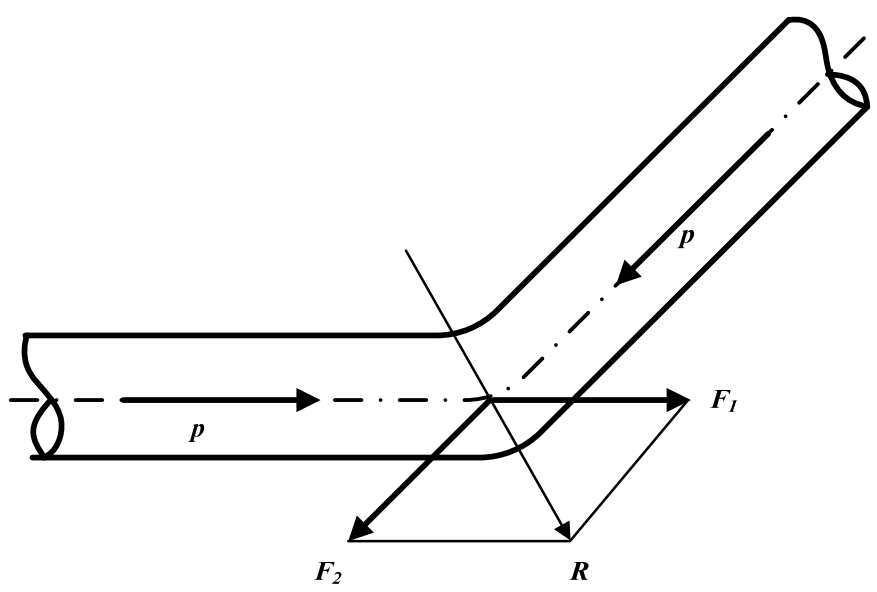

Figure 2. Elbow force diagram.

According to the above formula, $R$ is constant if $p$ is constant while the bend deformation and stress are static. In the case where the pressure is pulsating, $p=p_{0}+\Delta p$. Hence, the resultant force of elbow should be:

$$
R=2\left(\frac{\pi d_{i}^{2}}{4}\right)\left(p_{0}+\Delta p\right) \sin \left(\frac{\beta}{2}\right)=2\left(\frac{\pi d_{i}^{2}}{4}\right) p_{0} \sin \left(\frac{\beta}{2}\right)+2\left(\frac{\pi d_{i}^{2}}{4}\right) \Delta p \sin \left(\frac{\beta}{2}\right)
$$

In the above formula, $p_{0}$ represents average pressure, $\mathrm{Pa} ; \Delta p$ represents amplitude of pressure pulsation, $\mathrm{Pa}$.

In Equation (8), the two terms represent the force generated by the static pressure on the elbow and the exciting force $\Delta R$ generated by the pressure pulsation, respectively.

$$
\Delta R=2\left(\frac{\pi d_{i}^{2}}{4}\right) \Delta p \sin \left(\frac{\beta}{2}\right)=2 S \Delta p \sin \left(\frac{\beta}{2}\right),
$$

In Equation (9), $\Delta p$ is pressure pulsation, the unit is $\mathrm{Pa}$; $S$ is cross sectional area of pipe, the unit is $\mathrm{m}^{2}$. 


\subsection{Model of Pipe and Constraints}

Due to the complexity of the BOG compressor piping system, the stress calculation using the beam model is relatively simple. The pipeline model includes the straight pipe model, elbow model and tee model. Constraint models include compressor nozzle constraints, valve seat constraints, and guidance constraints. The relevant details were explained in another article by one of the authors in reference [24].

\subsection{Stress Analysis Method}

This study applied the finite element method to analyze the stress of the BOG compressor piping system. Since large deformation and nonlinearity problems are not involved in the stress of BOG compressor piping, the advantages and disadvantages of ANSYS (ANSYS 2019 R3, ANSYS, Inc., Canonsburg, PA, USA), ABAQUS (ABAQUS 2020, ABUQUS Inc., Palo Alto, CA, USA) and CAESAR II (CAESAR II 2019 v11.00, COADE, Inc., Houston, TX, USA) software were compared, and CAESAR II software was judged to be more appropriate. Through engineering verification, the software can meet the accuracy of calculation, and we found that the CAESAR II software is superior in the case of a complicated piping system for its fast calculation speed and easy modeling processes.

\section{Assumed condition}

CAESAR II software performs the stress analysis on the assumption that [30]:

(a) The assumption of small deformation: in the cross section, the local deformation of the element under load is negligible;

(b) The plastic deformation and large deformation are not considered in the elastic range of the pipe material, which means the nonlinear problem of the pipe structure is not taken into account;

(c) In the process of loading the aircraft remains flat;

(d) Considering only the elastic changes and loads of the pipe, and Hooke's law applies to the full load range of the tubular section;

(e) Assuming that the points, the forces and moments acting on the structure are on their central axes;

(f) The rotational deformation of the system is small;

(g) The force is not affected by structural deformation.

2. Grid precision

For all pipes supported by the ground, whether the soil is covered or not, the distance between the nodes of the pipe with diameter greater than $304.8 \mathrm{~mm}$ should be less than or equal to 20 times the diameter of the pipe, and for a pipe diameter smaller than or equal to $304.8 \mathrm{~mm}$, the distance between the nodes should not be greater than 30 times the diameter of the pipe [32]. For pipes with support constraints, the nodes must be distributed at the pipe support, otherwise the nodes between the pipe supports produce the wrong longitudinal displacement because of the unbearable weight.

3. Mass matrix of piping system

The element mass matrix is:

$$
\left[M_{\mathrm{e}}\right]=\rho S l\left[\begin{array}{cccc}
\frac{13}{15} & \frac{11 l}{210} & \frac{9}{70} & \frac{-13 l}{420} \\
\frac{11 l}{210} & \frac{l^{2}}{105} & \frac{13 l}{420} & \frac{-l^{2}}{140} \\
\frac{9}{70} & \frac{13 l}{420} & \frac{13}{15} & -\frac{11 l}{210} \\
\frac{-13 l}{420} & \frac{-l^{2}}{140} & -\frac{111}{210} & \frac{l^{2}}{105}
\end{array}\right],
$$

The total mass matrix of the piping system is [26]:

$$
[M]=\sum_{e=1}^{m}[G]^{T}\left[M^{e}\right][G],
$$




\subsection{Natural Frequency and Excitation Frequency}

The natural frequency of piping system is expressed as [33-36]:

$$
W_{0}=\frac{y_{2}}{2 \pi} \sqrt{\frac{k}{m}}
$$

where $y_{2}=$ order of natural frequency, $y_{2}=1,2,3 \ldots ; k=$ stiffness of piping system; $m=$ mass of piping system

Excitation frequency refers to the number of vibrations of the vibrating object within a unit of time, its expression is:

$$
W_{1}=\frac{n m A}{60},
$$

where $n=$ compressor speed in RPM, r $/$ min; $m=$ number of cylinders; $A=$ action mode, $A=1$ for single-action, $A=2$ for dual-action.

\subsection{Pipe Stress and Model Calibration}

1. Stress calibration

The main loads acting on the LNG pipe system are as follows: self-weight, pressure temperature, restraints force at piping support, forced displacement. Primary stress and secondary stress of the pipe stress can be divided by the destruction forms of the pipe. ASME B31.3 "Process Piping" standard should be followed for the stress calibration of the LNG vaporizing station piping [37].

Primary stress is caused by external loads such as pressure and gravity, and should meet the following condition:

$$
S_{L} \leq S_{h}
$$

While secondary stress is generated by temperature difference and should satisfy the following condition:

$$
S_{E}=\left(S_{b}+4 S_{t}^{2}\right)^{0.5} \leq S_{A}=f_{R}\left(1.25 S_{c}+0.25 S_{h}\right),
$$

In Equations (14) and (15),

$S_{L}$, the sum of longitudinal stresses due to gravity and other continuous loads in the pipe;

$S_{h}$, allowable stress in the thermal state;

$S_{E}$, the calculated displacement stress range due to thermal expansion and end point displacement;

$S_{A}$, the allowable displacement stress range;

$S_{c}$, allowable stress in the cold state;

$f_{R}$, stress range factor;

$S_{b}$, the stress due to composite bending moment of pipe under thermal expansion, cold shrinkage and endpoint displacement;

$S_{t}$, the stress due to the torque of the pipe under the action of thermal expansion, cold shrinkage, and endpoint displacement.

\section{Model calibration}

As shown in Figure 3, in order to avoid resonance between the pipe and the equipment, the following is required [38-42]:

$$
\frac{W_{0}}{W_{1}}<0.8 \text { Or } \frac{W_{0}}{W_{1}}>1.2,
$$




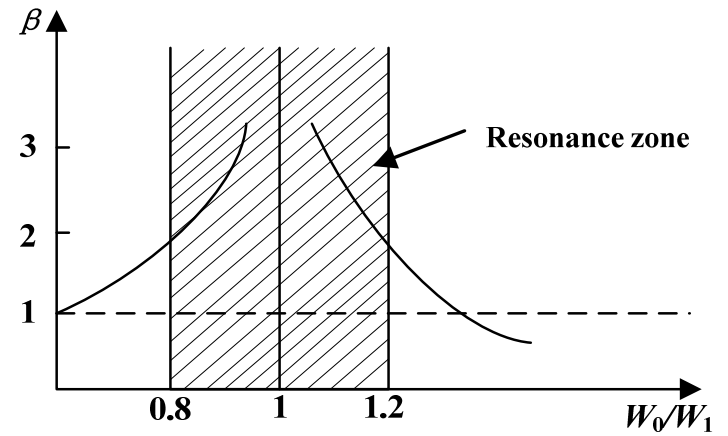

Figure 3. Resonance zone. (Note: $\beta=$ amplification factor; $W_{0}=$ natural frequency; $W_{1}=$ excitation frequency).

\section{Case Study}

\subsection{Project Overview}

As shown in Figure 4, the direct compression process was used to pressurize the BOG generated in the LNG storage tank and unloading system using a compressor. The pressurized BOG and the natural gas vaporized in the aero-thermal vaporizer were mixed in the main pipe, and after confluence, it was transported to a water-bath vaporizer and then warmed to above $-5^{\circ} \mathrm{C}$.

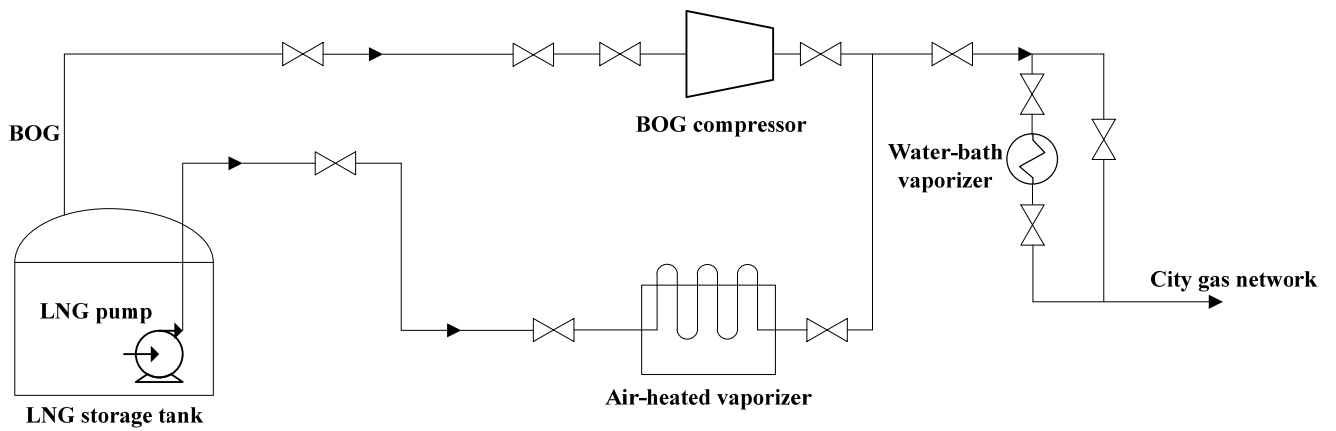

Figure 4. Schematic diagram of the process flow of LNG vaporizing station.

According to the maximum amount of BOG, two BOG compressors (RC1-Reciprocating compressor 1, RC2-Reciprocating compressor 2) were set up with the same displacement $\left(3000 \mathrm{Nm}^{3} / \mathrm{h}\right)$. As shown in Figure 5, the main elements of the BOG compressor piping system include the main suction pipe, main exhaust pipe, compressor inlet pipe and compressor outlet pipe. All the pipes are built above the ground.

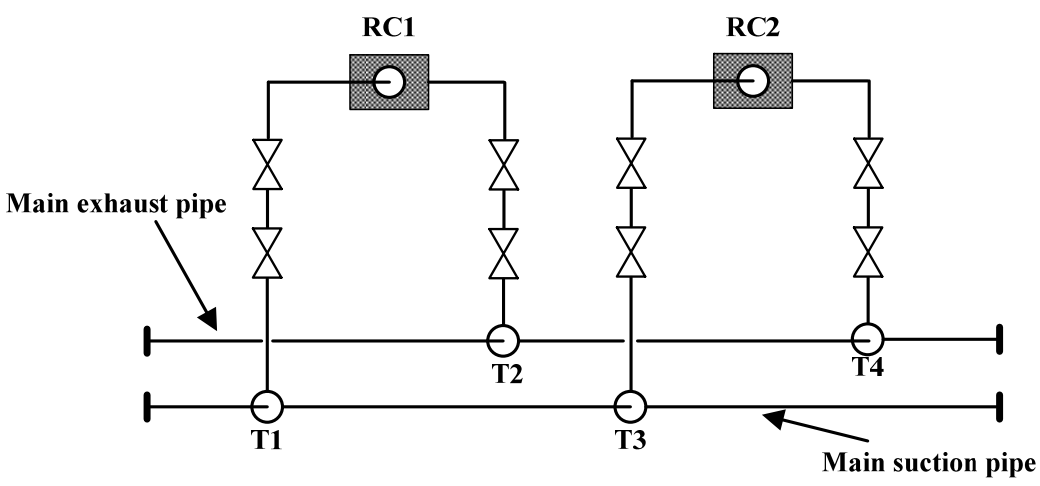

Figure 5. Sketch map of pipe distribution.

The operating condition (0 50 100\%) of the BOG compressor is regulated by the pressure of the LNG tank. If the BOG flow exceeds the compressor capacity, the pressures 
of the LNG storage tank and the main BOG pipe increase. If the pressure exceeds the set point of the control valve, the control valve will turn on, and the extra BOG will be delivered to the torch and burned. In the case of normal operation (no unloading operation), only one BOG compressor is needed. During the unloading operation, the amount of BOG is several times that of the normal condition, and two compressors are required to work at the same time. The parameter of the pipes can be seen in Table 1.

Table 1. Parameters of pipes.

\begin{tabular}{ccccc}
\hline Pipe Type & $\begin{array}{c}\text { Main } \\
\text { Suction Pipe }\end{array}$ & $\begin{array}{c}\text { Main Exhaust } \\
\text { Pipe }\end{array}$ & $\begin{array}{c}\text { Compressor } \\
\text { Inlet Pipe }\end{array}$ & $\begin{array}{c}\text { Compressor } \\
\text { Outlet Pipe }\end{array}$ \\
\hline Material & 06Cr19Ni10 & 06Cr19Ni10 & 06Cr19Ni10 & 06Cr19Ni10 \\
Diameter $(\mathrm{mm})$ & 219 & 219 & 219 & 219 \\
Thickness $(\mathrm{mm})$ & 6.0 & 6.0 & 6.0 & 6.0 \\
Insulation thickness $(\mathrm{mm})$ & 30 & 30 & 30 & 30 \\
Fluid density $\left(\mathrm{kg} / \mathrm{m}^{3}\right)$ & 0.75 & 0.75 & 0.75 & 0.75 \\
Installation temperature $\left({ }^{\circ} \mathrm{C}\right)$ & 20 & 20 & 20 & 20 \\
Operation temperature $\left({ }^{\circ} \mathrm{C}\right)$ & -152 & -68 & -152 & -68 \\
Operation pressure $(\mathrm{MPa})$ & 0.115 & 0.6 & 0.115 & 0.6 \\
\hline
\end{tabular}

\subsection{Numerical Simulation}

According to the actual data of the LNG vaporizing station, the corresponding pipe model was established and the constraints were set. The main constraints of the pipeline are: compressor nozzle, valve seat constraints and guidance constraints.

The nozzle of the BOG compressor and the equipment were connected through the flange. In general, the compressor nozzle flange was simulated as a fixed point (Anchor), indicating that the line displacements and angular displacements in the direction of $X, Y$ and $\mathrm{Z}$ are constrained, as shown in Figure 6. Considering the effect of cold shrinkage, the initial displacement at the nozzle was set to $0.174 \mathrm{~mm}$.

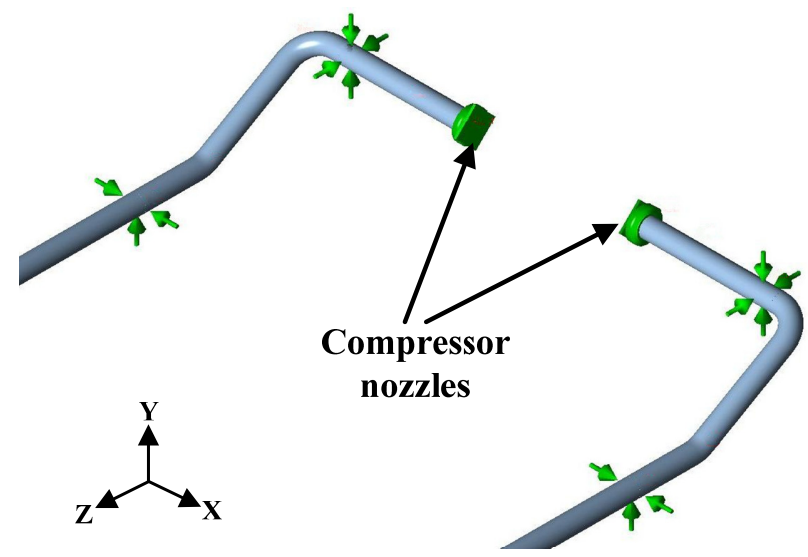

Figure 6. The model of compressor nozzle.

The function of valve seat is the same as the load-bearing bracket and could hold back the downward displacement of the pipe. In CAESAR II software, the valve seat is represented by a unidirectional upward constraint $(+Y)$, which means that the restraining force acts in the $+Y$ direction of the pipe. As the pipe slides relative to the valve seat, a friction model should be built and the friction coefficient between the valve seat and the pipe need to be defined. Figure 7 shows the valve seat model. 


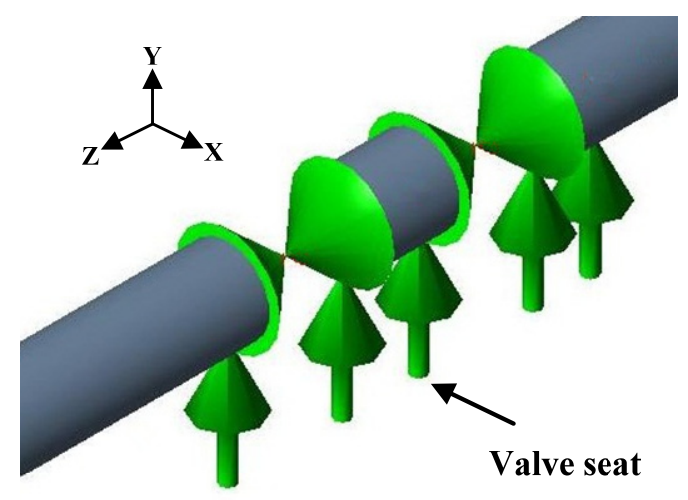

Figure 7. The model of valve seat.

In the LNG vaporizing station, four-directional guide are usually used to constrain the displacement of the pipeline. The four-directional guide can better control the resonance, and it also needs to define the friction coefficient. In addition, the size of the gap can be defined. When the installation is completed, there is no contact between the pipe and the support, which is a passive constraint. However, when the pipe is thermally displaced, the gap between the two can be closed to become an active constraint. The gap between the pipe and the support was $3 \mathrm{~mm}$ in this study. The four-directional guide model is shown in Figure 8.

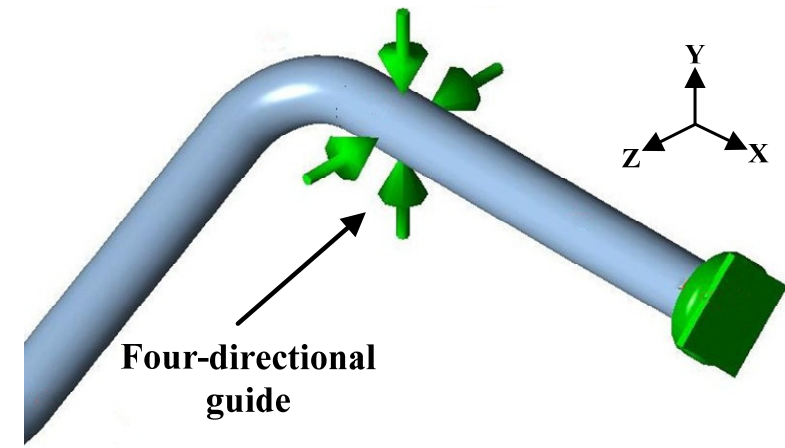

Figure 8. The model of four-directional guide.

The established model of overall piping system can be seen in Figure 9.

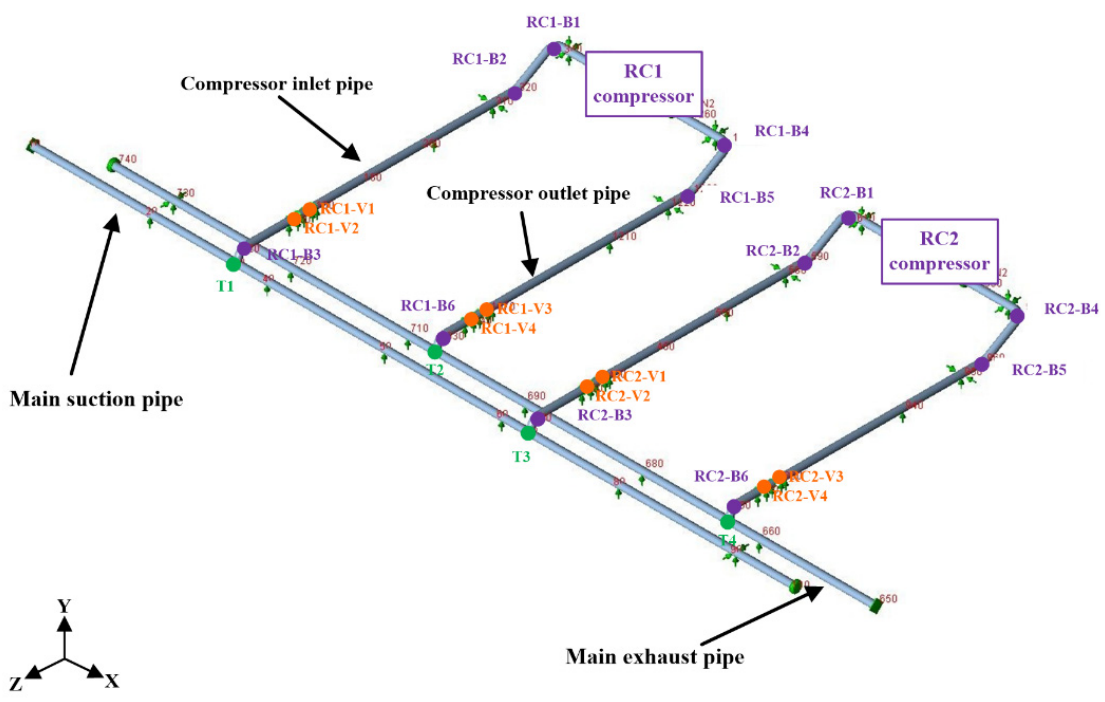

Figure 9. The model of overall piping system. 


\section{Results}

\subsection{Static Stress Analysis Result}

In the case of RC1 and RC2 running together, the stress and displacement distribution of the pipes were as follows.

1. Stress analysis result

The primary stress, secondary stress, comprehensive stress of main suction pipe, main exhaust pipe, compressor inlet pipe and compressor outlet pipe are shown in Figure 10, and representative pipe elbow and tee locations are marked. As fluid passed through pipe elbow and tee, the flow rate and the pressure in the pipe increased, which resulted in an increase in stress at these locations.

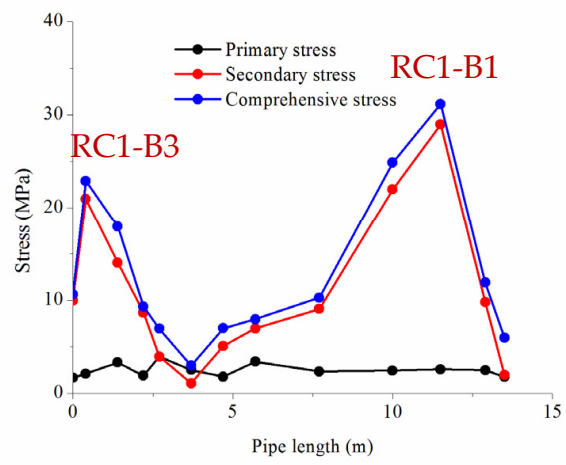

(a)

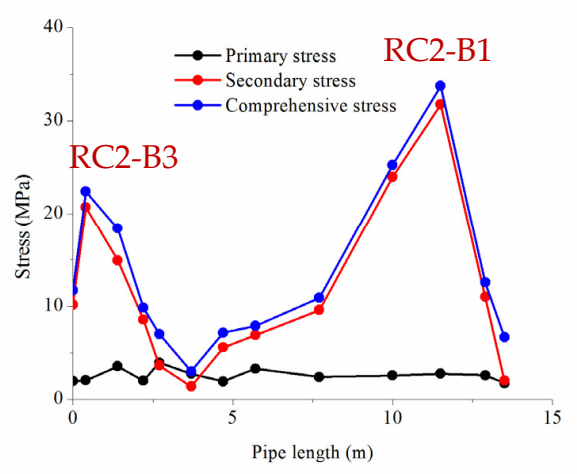

(c)

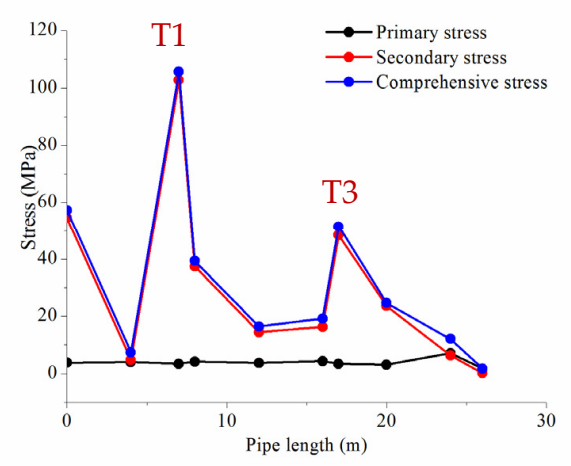

(e)

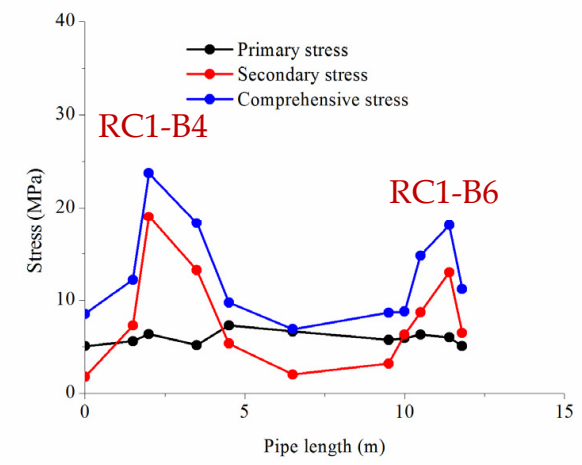

(b)

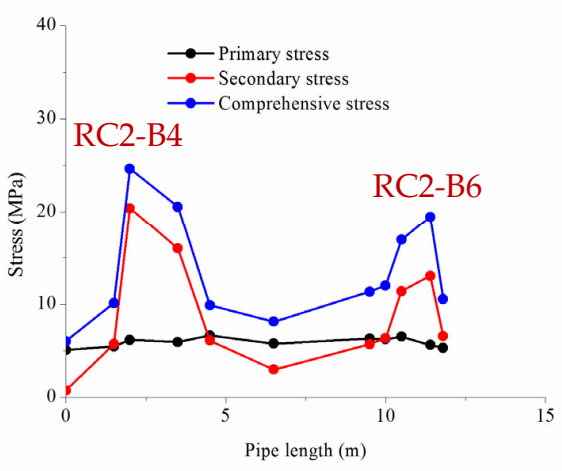

(d)

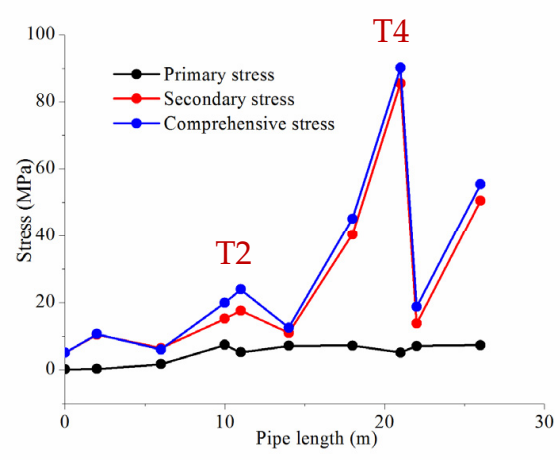

(f)

Figure 10. Stress distribution: (a) Compressor (RC1) inlet pipe; (b) Compressor (RC1) outlet pipe; (c) Compressor (RC2) inlet pipe; (d) Compressor (RC2) outlet pipe; (e) Main suction pipe; (f) Main exhaust pipe. 
The following conclusions can be drawn from Figure 10:

a. The stress distribution of the same type of pipe is basically the same, and the larger stress is produced at the tee or the elbow.

b. The comprehensive stress of each pipe is the largest, the secondary stress is slightly less than the comprehensive stress, and the primary stress is the smallest. It shows that the temperature difference (Secondary stress) had the greatest influence on the pipe stress for the low-temperature pipeline in the LNG vaporizing station.

c. The stress of compressor inlet pipe is slightly greater than the compressor outlet pipe, the stress of main suction pipe is slightly larger than the main exhaust pipe (The temperature of BOG in the compressor inlet pipe and main suction pipe is lower than the compressor inlet pipe and main exhaust pipe, but the pressure of compressor outlet pipe and main exhaust pipe is larger), indicating that the impact of temperature difference on the stress is greater than the impact of pressure.

2. Displacement analysis

In the BOG compressor piping system, the pipes have axial, horizontal and longitudinal displacements. Axial displacement and longitudinal displacement are mainly caused by the expansion and contraction of the pipe, and the horizontal displacement is mainly caused by gravity. The displacement of each pipe can be seen in Figure 11.

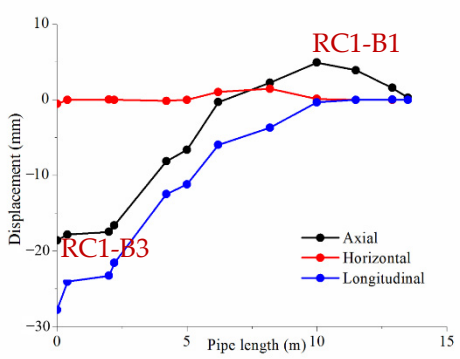

(a)

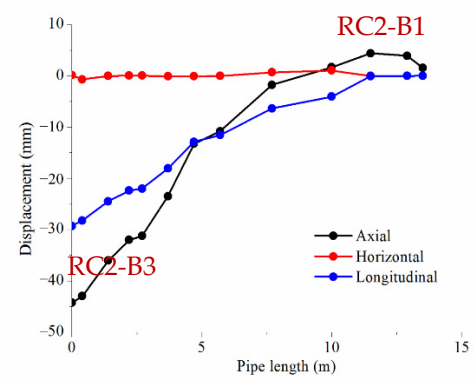

(c)

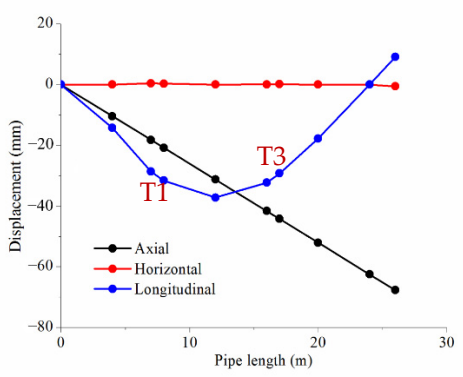

(e)

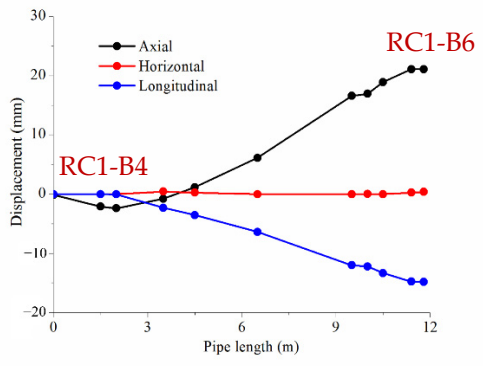

(b)

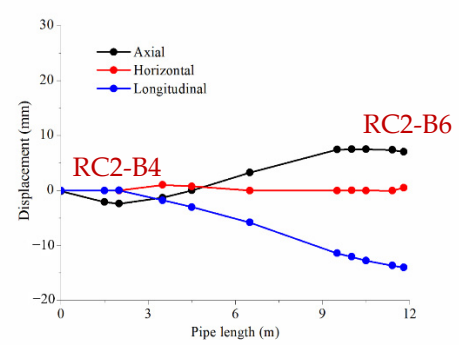

(d)

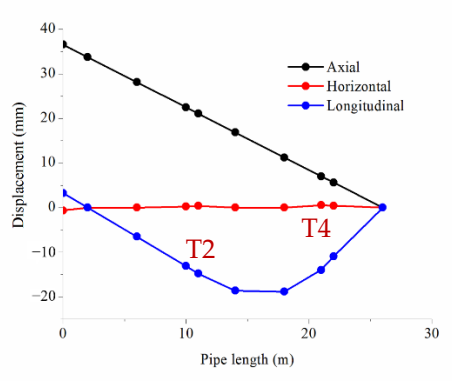

(f)

Figure 11. Displacement distribution: (a) Compressor (RC1) inlet pipe; (b) Compressor (RC1) outlet pipe; (c) Compressor (RC2) inlet pipe; (d) Compressor (RC2) outlet pipe; (e) Main suction pipe; (f) Main exhaust pipe. 
The following conclusions can be drawn from Figure 11:

a. The horizontal displacement of the pipe was restricted by the bracket and support, so the horizontal displacement of the pipe was the smallest.

b. Compressor inlet pipe and main suction pipe experienced larger negative axial displacements and longitudinal displacements, and the displacement was recorded to be as high as $70 \mathrm{~mm}$ because the low temperature of BOG in the pipe, which caused the cold contraction of the pipe.

\subsection{Harmonic Analysis Result}

A harmonic analysis of the pipe was performed using the dynamic analysis module in CAESAR II software, which loads the unbalanced exciting force on the piping system. The compressor speed in RPM is $480 \mathrm{r} / \mathrm{min}$, characteristic of a single cylinder single-action equipment, and the sound velocity is $374 \mathrm{~m} / \mathrm{s}$.

\section{RC1 runs separately}

The calculation results of unbalanced exciting force caused by RC1 compressor in piping system can be seen in Table 2, while the stress distribution of pipes under static action and pressure pulsation action are shown in Figure 12.

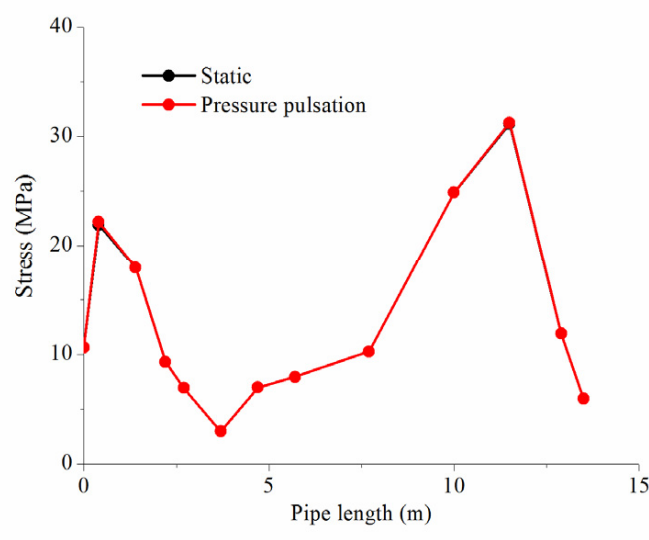

(a)

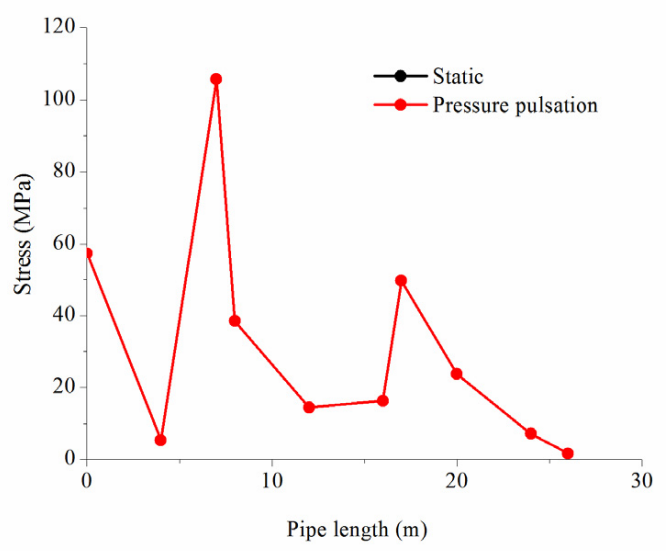

(c)

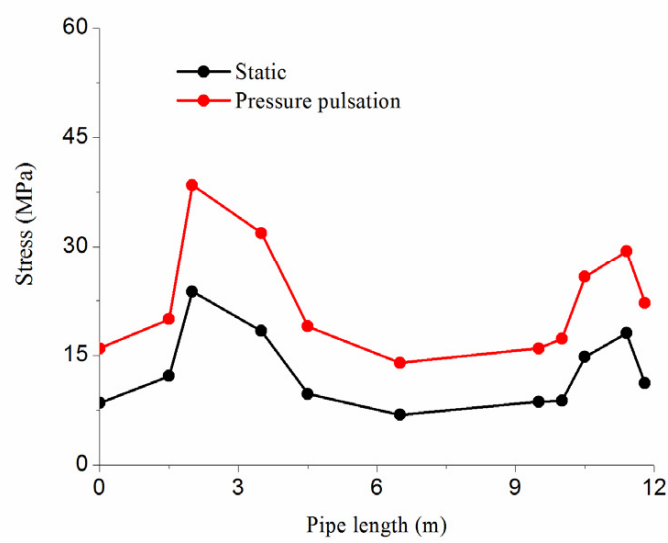

(b)

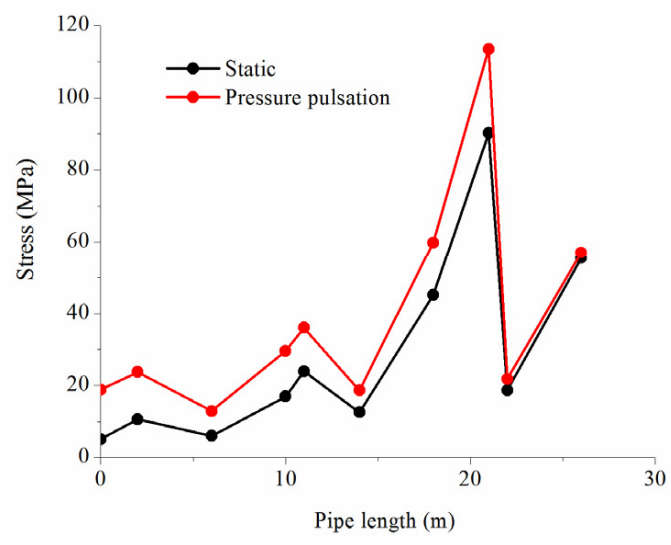

(d)

Figure 12. Stress distribution of pipes under static action and pressure pulsation action: (a) Compressor (RC1) inlet pipe; (b) Compressor (RC1) outlet pipe; (c) Main suction pipe; (d) Main exhaust pipe. 
Table 2. Calculation results of unbalanced exciting force caused by RC1 compressor.

\begin{tabular}{cccccc}
\hline Pipe Type & Location & $\begin{array}{c}\text { Pressure } \\
\text { Pulsation } \\
\mathbf{( P a )}\end{array}$ & $\begin{array}{c}\text { Unbalanced } \\
\text { Exciting } \\
\text { Force (N) }\end{array}$ & Direction & $\begin{array}{c}\text { Phase } \\
\text { Angle } \\
\text { (Degree) }\end{array}$ \\
\hline Compressor & RC1-B1 & $67,394.59$ & -3207.53 & $\mathrm{X}$ & 0 \\
inlet pipe & RC1-B2 & $117,453.19$ & -2046.08 & $\mathrm{Z}$ & 3.21 \\
& RC1-B3 & $402,706.47$ & $19,166.12$ & $\mathrm{Y}$ & 15.42 \\
\hline Compressor & RC1-B4 & $46,248.18$ & 2201.10 & $\mathrm{X}$ & 0 \\
outlet pipe & RC1-B5 & $80,599.89$ & -1404.08 & $\mathrm{Z}$ & 2.21 \\
& RC1-B6 & $247,275.66$ & $11,768.66$ & $\mathrm{Y}$ & 10.89 \\
\hline Main suction pipe & $\mathrm{T} 1$ & $415,325.64$ & $-19,766.71$ & $\mathrm{Z}$ & 16.04 \\
Main exhaust pipe & $\mathrm{T} 2$ & $250,621.06$ & $-11,927.87$ & $\mathrm{Z}$ & 11.73 \\
\hline
\end{tabular}

2. RC1 and RC2 run together

The calculation results of unbalanced exciting force caused by RC2 compressor can be seen in Table 3, and the summary of maximum stress and location can be seen in Table 4.

Table 3. Calculation results of unbalanced exciting force caused by RC2 compressor.

\begin{tabular}{cccccc}
\hline Pipe Type & Location & $\begin{array}{c}\text { Pressure } \\
\text { Pulsation } \\
\mathbf{( P a )}\end{array}$ & $\begin{array}{c}\text { Unbalanced } \\
\text { Exciting } \\
\text { Force (N) }\end{array}$ & Direction & $\begin{array}{c}\text { Phase } \\
\text { Angle } \\
\text { (Degree) }\end{array}$ \\
\hline Compressor & RC1-B1 & $67,391.59$ & -3207.53 & $\mathrm{X}$ & 0 \\
inlet pipe & RC1-B2 & $117,453.19$ & -2046.07 & $\mathrm{Z}$ & 3.21 \\
& RC1-B3 & $402,706.47$ & $19,166.12$ & $\mathrm{Y}$ & 15.42 \\
\hline Compressor & RC1-B4 & $46,248.18$ & 2201.10 & $\mathrm{X}$ & 0 \\
outlet pipe & RC1-B5 & $80,599.89$ & -1404.08 & $\mathrm{Z}$ & 2.21 \\
& RC1-B6 & $247,275.69$ & $11,768.66$ & $\mathrm{Y}$ & 10.89 \\
\hline Main suction pipe & $\mathrm{T} 3$ & $415,325.64$ & $-19,766.71$ & $\mathrm{Z}$ & 16.04 \\
Main exhaust pipe & $\mathrm{T} 4$ & $254,731.38$ & $-12,123.50$ & $\mathrm{Z}$ & 11.73 \\
\hline
\end{tabular}

Table 4. Summary of maximum stress and location.

\begin{tabular}{cccc}
\hline Pipe Type & $\begin{array}{c}\text { Maximum Stress } \\
(\mathbf{M P a})\end{array}$ & Location & $\begin{array}{c}\text { Allowable Stress } \\
\text { (MPa) }\end{array}$ \\
\hline RC1 compressor inlet pipe & 31.76 & RC1-B1 & \\
RC1 compressor outlet pipe & 31.85 & RC1-B4 & \\
RC2 compressor inlet pipe & 34.14 & RC2-B1 & 205.5 \\
RC2 compressor outlet pipe & 44.91 & RC2-B4 & \\
Main suction pipe & 105.99 & T1 & \\
Main exhaust pipe & 108.50 & T4 & \\
\hline
\end{tabular}

It can be seen from Figure 12 that the unbalanced exciting force has great influence on the stress of the compressor outlet pipe and the main exhaust pipe, and has little influence on the stress of the compressor inlet pipe and the main suction pipe. Moreover, although the unbalanced exciting forces are produced at the elbows and the tees, the stresses of the elbows and the tees are greatly influenced, and it has a certain impact on the straight pipes.

It can be seen from Table 4 that in the case of double-compressor operation, the maximum stress of the RC1 compressor outlet pipe and main exhaust pipe would be lower than those of the case of $\mathrm{RC} 1$ single compressor operation. However, this has little effect on the stress of the RC1 compressor inlet pipe and the main suction pipe.

\subsection{Modal Analysis Result}

The speed of the compressor is $480 \mathrm{r} / \mathrm{min}$ and the number of cylinders is 1 , so the excitation frequency is $8 \mathrm{~Hz}$. Therefore, the resonance region of the piping system is 
6.4 9.6 Hz. Because the natural frequency of the pipe is positively correlated with the order, the first-order natural frequency of the pipe should be of no less than $9.6 \mathrm{~Hz}$ if the resonance region is avoided. The modal analysis module of CAESAR II software was used to perform a modal analysis, for which the analysis parameters are shown in Table 5, and the results are shown in Figure 13.

Table 5. Parameters of modal analysis.

\begin{tabular}{cc}
\hline Parameter & Content \\
\hline Cut-off frequency & $200 \mathrm{HZ}$ \\
Mass model & Lumped mass model \\
Estimated value of the effective number of the eigenvalues & 8 \\
Jacobi scanning tolerance & $10^{-12}$ \\
Decomposition singular tolerance & $10^{10}$ \\
Frequency array space & 100 \\
\hline
\end{tabular}

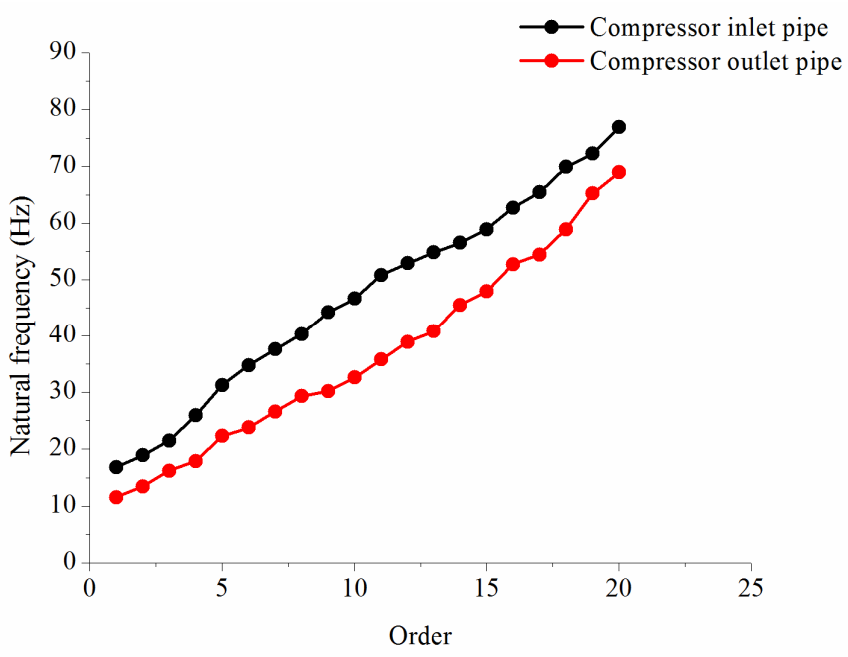

Figure 13. Natural frequency of compressor inlet pipe and outlet pipe.

It can be seen from Figure 13 that the natural frequency of the compressor inlet pipe is higher than that of the outlet pipe. The first-order natural frequency of the compressor inlet pipe is $16.81 \mathrm{~Hz}$, while the first order natural frequency of the compressor outlet pipe is $11.53 \mathrm{~Hz}$, both of which are larger than $9.6 \mathrm{~Hz}$, meeting the requirement of modal calibration. Because the lowest natural frequency of the BOG compressor piping system is $11.53 \mathrm{~Hz}$, the condition that the pipe does not have structural resonance is that the compressor speed is less than $541 \mathrm{r} / \mathrm{min}$.

\section{Discussion}

In this paper, several factors influencing the stress of the pipe are analyzed: pipe support spacing, pressure and elbow angle, and the measures of stress reduction are put forward.

\subsection{Influence of Pipe Support Spacing}

In piping design, the setting of the support has a great influence on the stress of the pipe. This paper used the RC1 compressor outlet pipe as an example, assumed the distance between the elbow and the support 1 to be $x \mathrm{~mm}$, and the distance between the support 1 and the support 2 to be $\mathrm{ym}$, as shown in Figure 14. Pipe stress under different support spacing can be seen in Table 6. 


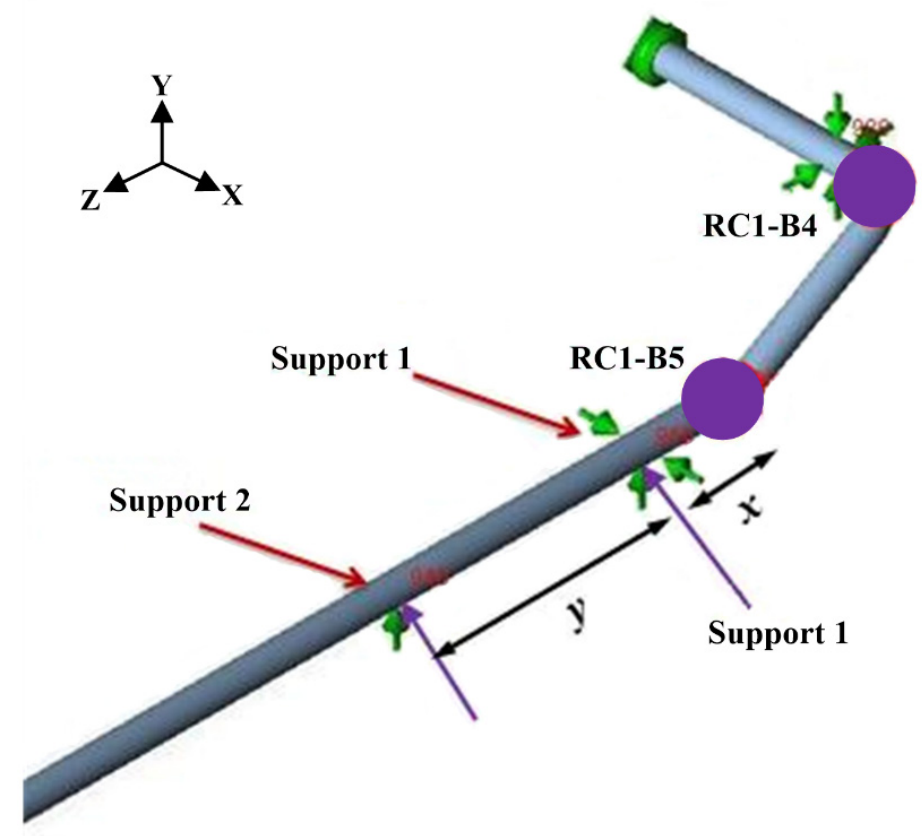

Figure 14. Layout of the pipe support of the compressor outlet pipe.

Table 6. Pipe stress under different support spacing.

\begin{tabular}{ccc}
\hline Variable & Spacing $(\mathbf{m m})$ & Stress $\mathbf{( M P a )}$ \\
\hline & 400 & 39.76 \\
$x$ & 600 & 37.6 \\
& 800 & 36.04 \\
& 1000 & 38.13 \\
& 1200 & 40.52 \\
\hline & 1000 & 37.53 \\
& 1500 & 37.75 \\
& 2000 & 38.13 \\
& 2500 & 38.24 \\
\end{tabular}

As shown in Table 6, with the increase in $x$ (the distance between the elbow and the support 1), the pipe stress tends to decrease firstly and then increase. This is because the support limits the deformation of the elbow so that it cannot reduce the stress through its own flexible deformation when the distance is small. When the spacing increases, the elbow can offset part of the stress through its own flexible deformation. When the spacing continues to increase, the stress of pipe increases as the suspension section of the pipe is too long.

For this paper, the pipe stress is the smallest when $\mathrm{x}$ is $800 \mathrm{~mm}$. On the other hand, the pipe stress increases with the increase in $y$ (the distance between the support 1 and the support 2), but the increase is not significant.

\subsection{Influence of Pressure}

The operation pressure of the compressor outlet pipe is $0.6 \mathrm{MPa}$, and the design pressure of the pipe is $1 \mathrm{MPa}$. The pressure of pipeline in actual operation is lower than the design pressure, and the pressure is regulated by frequency-conversion control. This paper used the $\mathrm{RC} 1$ compressor outlet pipe as an example, nd the stress of a pipe with a pressure of 0.1-1.0 MPa was discussed. Because the maximum stress is produced at RC1-B4, it was used as the research object. The unbalanced exciting force and stress of RC1-B4 under different pressures are shown in Figure 15. 


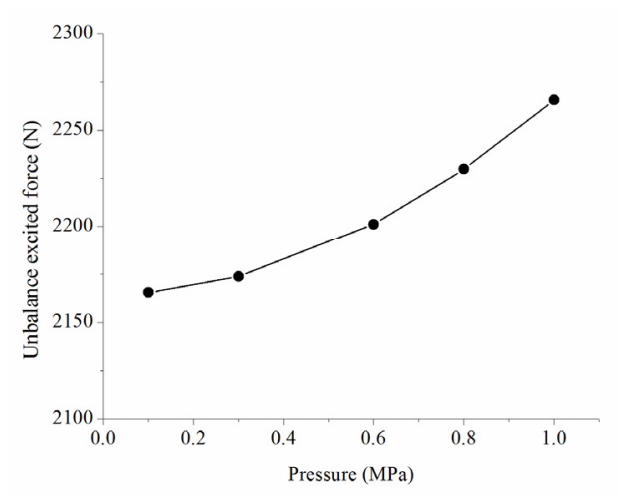

(a)

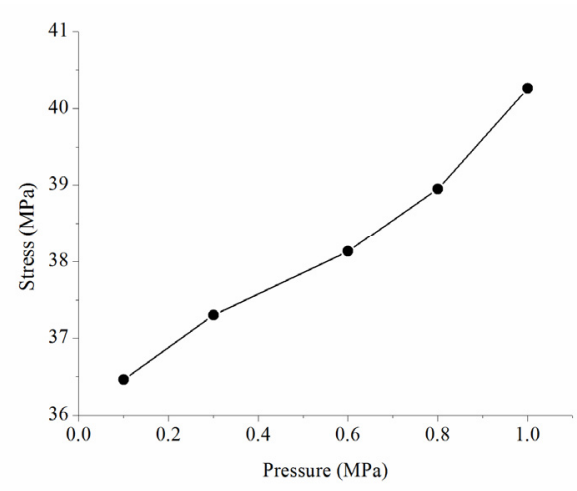

(b)

Figure 15. Unbalanced exciting force and stress of RC1-B4 under different pressures (a) Unbalanced exciting force; (b) Stress.

It can be seen from Figure 15 that the unbalanced exciting force increases with the increase in pressure, and the higher the pressure, the greater the amplitude of the increase I the unbalanced exciting force. Moreover, the stress of the pipe increases with the increase in pressure.

\subsection{Influence of Elbow Angle}

As shown in Figure 16, the design value of the bend angle $\alpha$ is $30^{\circ}$, and the angle $\alpha$ $\left(30^{\circ}-90^{\circ}\right)$ between the compressor inlet (outlet) pipe and the ground was changed in order to study the influence of the bend angle on the pipe stress. Furthermore, RC1-B4 was still used as an analysis object, and the stresses at RC1-B4 with different elbow angles are shown in Table 7.

It can be seen from Table 7 that with the increase in the elbow angle, the unbalanced exciting force also increases. However, the stress at RC1-B4 decreases first and then increases with the increase in angle $\alpha$. This indicates that the pipe stress is not only influenced by the unbalanced exciting force, but is also related to the structure of pipe itself. When the angle of the bend is $60^{\circ}$, the stress at RC1-B4 is the least.

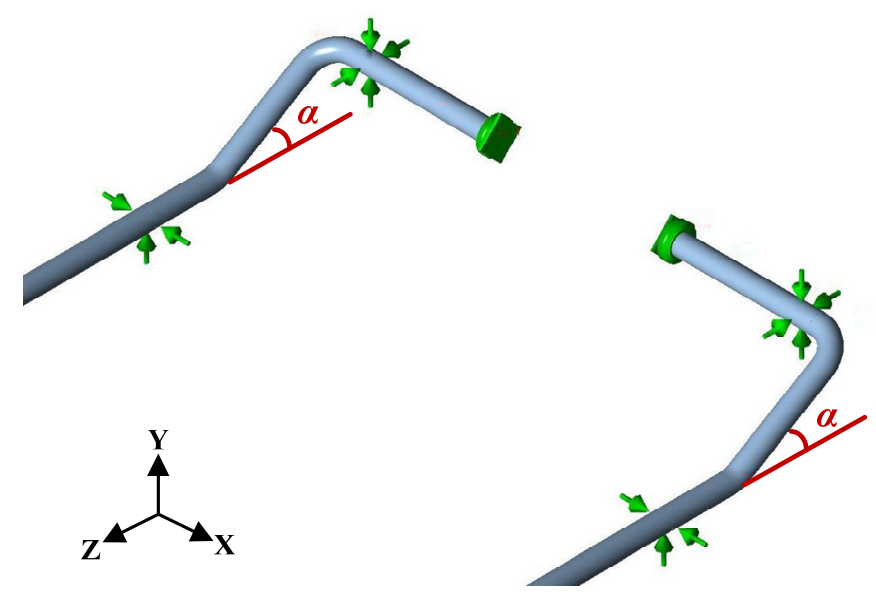

Figure 16. The angle $\alpha$ between the compressor inlet (outlet) pipe and ground. 
Table 7. Pipe stress under different support spacing.

\begin{tabular}{cccc}
\hline $\begin{array}{c}\text { Elbow Angle } \\
\text { (Degree) }\end{array}$ & $\begin{array}{c}\text { Pressure Pulsation } \\
\mathbf{( P a )} \text { at RC1-B5 }\end{array}$ & $\begin{array}{c}\text { Unbalanced Exciting } \\
\text { Force at RC1-B5 } \mathbf{( N )}\end{array}$ & $\begin{array}{c}\text { Stress of RC1-B4 } \\
\mathbf{( M P a )}\end{array}$ \\
\hline 30 & $80,599.89$ & -1404.08 & 38.13 \\
35 & $80,599.89$ & -1631.31 & 39.49 \\
40 & $80,599.89$ & -1855.44 & 39.16 \\
45 & $80,599.89$ & -2076.04 & 40.51 \\
50 & $80,599.89$ & -2292.68 & 42.73 \\
55 & $80,599.89$ & -2504.96 & 39.04 \\
60 & $80,599.89$ & -2712.47 & 34.92 \\
65 & $80,599.89$ & -2914.82 & 39.71 \\
70 & $80,599.89$ & -3111.62 & 42.43 \\
75 & $80,599.89$ & -3302.49 & 45.07 \\
80 & $80,599.89$ & -3487.08 & 47.91 \\
85 & $80,599.89$ & -3665.04 & 48.30 \\
90 & $80,599.89$ & -3836.01 & 49.46 \\
\hline
\end{tabular}

\subsection{Stress Reduction Measures}

According to the analysis of influence of elbow angle on pipe stress, the stress can be reduced by optimizing the elbow angle in the design stage. However, for pipes that are already running, pipe stress can be reduced by adding constraints and setting expansion joints.

In order to show the effect of stress reduction measures more intuitively, in 2016, Hongfang Lu first proposed the concept of the stress-reduction factor, which can be defined as follows: In pipeline engineering, the ratio of the change of stress caused by the stress reduction measures and the stress before the retrofit. Its expression is [43]:

$$
K_{R}=\frac{\sigma_{2}-\sigma_{1}}{\sigma_{1}}=\frac{\Delta \sigma}{\sigma_{1}},
$$

where $K_{R}=$ stress reduction factor; $\sigma_{1}=$ the stress before the retrofit; $\sigma_{2}=$ the stress after the retrofit; $\Delta \sigma=$ the difference between the stress before the retrofit and the stress after the retrofit.

When $K_{R}$ is in the range of $(-1,0]$, the greater the value is, the worse the stress reduction effect is, when $K_{R}$ is in the range of $[0,+\infty)$, the stress reduction measure is invalid.

1. Add constraint

In this paper, the $\mathrm{T} 1$ in the compressor piping system was taken as an example, and a constraint was added near T1. The constraint positions are shown in Figure 17. The stress reduction effects are shown in Table 8.

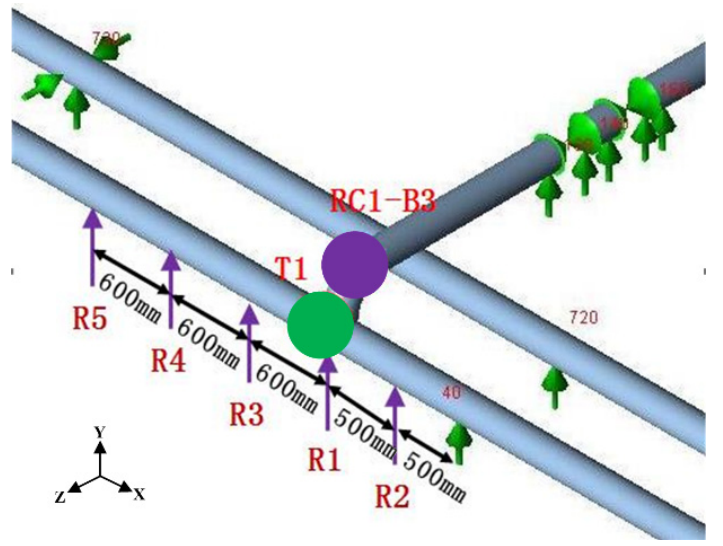

Figure 17. Constraint positions near T1. 
Table 8. Pipe stress after adding constraints.

\begin{tabular}{cccccc}
\hline $\begin{array}{c}\text { Position of } \\
\text { Constraint }\end{array}$ & $\begin{array}{c}\text { Constraint } \\
\text { Type }\end{array}$ & $\begin{array}{c}\text { Constraint } \\
\text { Expression }\end{array}$ & $\begin{array}{c}\text { Stress before } \\
\text { Adding } \\
\text { Constraint } \\
\text { (MPa) }\end{array}$ & $\begin{array}{c}\text { Stress after } \\
\text { Adding } \\
\text { Constraint } \\
\text { (MPa) }\end{array}$ & $\begin{array}{c}\text { Stress } \\
\text { Reduction } \\
\text { Factor } K_{\boldsymbol{R}}\end{array}$ \\
\hline R1 & & $+\mathrm{Y}$ & & 126.21 & 0.19 \\
R2 & Unidirectional & $+\mathrm{Y}$ & & 103.96 & -0.02 \\
R3 & constraint & $+\mathrm{Y}$ & 105.68 & 91.63 & -0.13 \\
R4 & & $+\mathrm{Y}$ & & 96.75 & -0.08 \\
R5 & & $+\mathrm{Y},+\mathrm{Z},-\mathrm{Z}$ & & 102.80 & -0.03 \\
\hline R1 & & $+\mathrm{Y},+\mathrm{Z},-\mathrm{Z}$ & & 133.48 & 0.26 \\
R2 & Three- & $+\mathrm{Y},+\mathrm{Z},-\mathrm{Z}$ & 105.68 & 101.47 & -0.04 \\
R3 & direction & $+\mathrm{Y},+\mathrm{Z},-\mathrm{Z}$ & & 86.32 & -0.18 \\
R4 & constraint & $+\mathrm{Y},+\mathrm{Z},-\mathrm{Z}$ & & 100.52 & -0.08 \\
R5 & & & & & -0.05 \\
\hline
\end{tabular}

It can be seen from Table 8 that regardless of what kind of restraint is added at R1, the stress cannot be reduced, but the stress will be increased. The stress can be reduced by adding any constraint at R2, R3, R4 and R5. Among them, the stress-reduction effect of adding three-direction constraint is better than that of a unidirectional constraint, and adding a constraint at R3 is the best way to reduce stress. Therefore, a three-direction constrained steel bracket can be added at R3 to reduce the stress in the actual project.

\section{Set expansion joint}

In the flexible design of compressor piping, it is not suitable to use a natural compensator with elbow. Generally, expansion joints are used to reduce pipeline stress and increase pipeline flexibility. Bellows' expansion joint mainly depends on the deformation of bellows that absorbs displacement, and can set a larger diameter and bear higher pressure. Therefore, the bellows' expansion joint should be considered in the compressor nozzle. Considering that the stiffness of bellows is small, the pressure that it can bear is limited. Therefore, it is necessary to set up support (Fixed point) at the two ends of expansion joint to withstand the pressure and thrust, as shown in Figure 18.

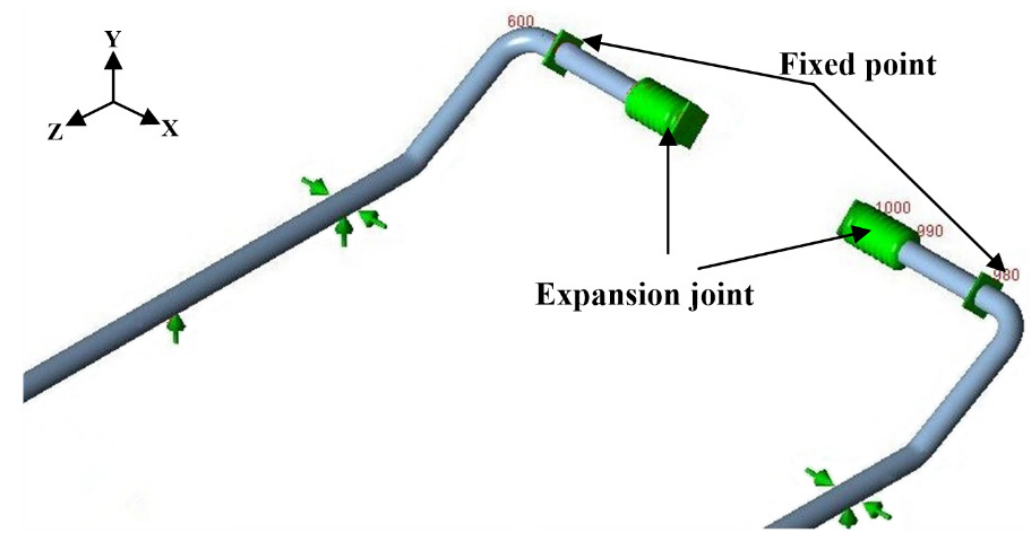

Figure 18. Schematic diagram of the expansion joint model.

The material used to construct the expansion joint was $06 \mathrm{Cr} 19 \mathrm{Ni10}$, the length $L$ was $500 \mathrm{~mm}$, the axial stiffness $A$ was $200 \mathrm{~N} / \mathrm{mm}, 300 \mathrm{~N} / \mathrm{mm}, 400 \mathrm{~N} / \mathrm{mm}, 500 \mathrm{~N} / \mathrm{mm}$, $600 \mathrm{~N} / \mathrm{mm}$, and the horizontal stiffness $T$ was:

$$
T=\frac{2}{3} \times\left(\frac{D}{L}\right)^{2} \times A,
$$

where $D=$ diameter of bellows, $\mathrm{mm} ; L=$ length of bellows, $\mathrm{mm} ; A=$ axial stiffness, $\mathrm{N} / \mathrm{mm}$. 
The stresses of RC1-B4 after adding different kinds of expansion joints are shown in Table 9. It can be seen from Table 9 that the stiffness of the expansion joint greatly influences the compensation effect. The smaller the stiffness of expansion joint, the better the compensation effect. However, the smaller the stiffness, the more difficult the design of the expansion joint will be. Hence, the performance and cost of the expansion joint should be considered synthetically. Therefore, the expansion joint with an axial stiffness of $300 \mathrm{~N} / \mathrm{mm}$ is more suitable. In addition to reducing the pipe stress, the expansion joint can also reduce the displacement of the pipe. Taking the axial displacement of the inlet pipe and outlet pipe of the RC1 compressor as an example, the displacement comparison before and after adding the expansion joint is shown in Figure 19. It can be seen from Figure 19 that after the expansion joint is added, the displacements of the compressor inlet and outlet pipes become markedly reduced, and the displacement can be reduced by up to $14 \mathrm{~mm}$.

Table 9. The stresses of RC1-B4 after adding different kinds of expansion joints.

\begin{tabular}{cccc}
\hline $\begin{array}{c}\text { Axial Stiffness } \\
\text { (N/mm) }\end{array}$ & $\begin{array}{c}\text { Stress before } \\
\text { Adding Expansion } \\
\text { Joint (MPa) }\end{array}$ & $\begin{array}{c}\text { Stress after Adding } \\
\text { Expansion Joint } \\
\mathbf{( M P a )}\end{array}$ & $\begin{array}{c}\text { Stress Reduction } \\
\text { Factor } \boldsymbol{K}_{\boldsymbol{R}}\end{array}$ \\
\hline 200 & & 25.93 & -0.32 \\
300 & 38.13 & 30.89 & -0.19 \\
400 & & 35.08 & -0.08 \\
500 & & 36.60 & -0.04 \\
600 & & 36.61 & -0.04 \\
\hline
\end{tabular}

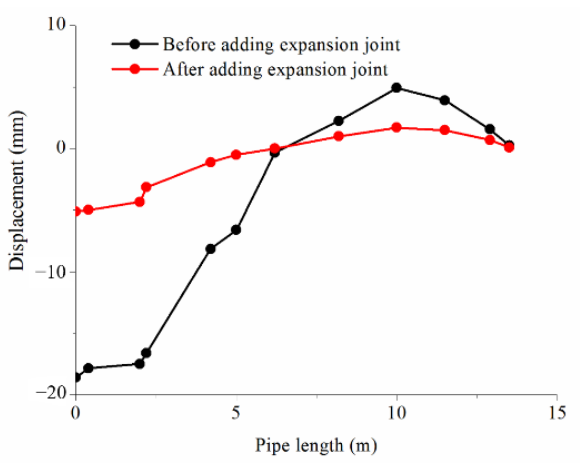

(a)

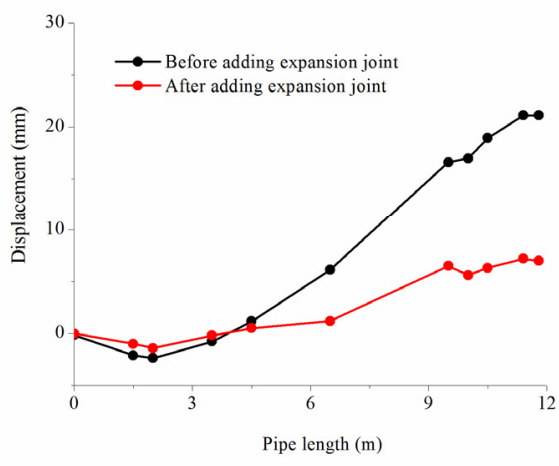

(b)

Figure 19. Displacement comparison before and after adding the expansion joint (a) RC1 compressor inlet pipe; (b) RC1 compressor outlet pipe.

\section{Conclusions}

In this paper, the pressure pulsation and the unbalanced exciting force in the reciprocating pump piping system were calculated by the separation variable method. Based on the beam model, the stress, harmonic and modal analysis of the BOG compressor piping system in the LNG vaporizing station were carried out using CAESAR II software. In addition, the influence factors of stress and the measures of stress reduction were discussed in this paper. The following conclusions were obtained:

1. For a BOG compressor piping system which belongs to low-temperature piping system, the secondary stress is much larger than the primary stress, indicating that the temperature difference plays a leading role in the stress of low-temperature pipes.

2. The unbalanced exciting force has great influence on the stress of the compressor outlet pipe and the main exhaust pipe, and has little influence on the stress of the compressor inlet pipe and the main suction pipe. 
3. Although unbalanced exciting forces are produced at the elbows and the tees, the stresses of the elbows and the tees are greatly influenced, which also has a certain impact on the straight pipes.

4. The pipe stress is not only influenced by the unbalanced exciting force, but by the structure of pipe itself.

5. Adding constraints or expansion joints can effectively reduce the pipe stress.

Author Contributions: Conceptualization, B.W. and K.H.; methodology, K.H., Z.Z. (Zhenwu Zhang) and L.F.; software, Z.Z. (Zhenwu Zhang), Y.Z. and H.G.; investigation, B.W. and K.H.; resources, B.W., Y.Z. and H.G.; data curation, Z.Z. (Zhang Zhi) and H.G.; writing-original draft preparation, B.W. and Y.Z.; writing - review and editing, Z.Z. (Zhi Zhang) and L.F.; visualization, K.H. and Z.Z. (Zhi Zhang); supervision, B.W.; project administration, B.W. All authors have read and agreed to the published version of the manuscript.

Funding: This research received no external funding.

Institutional Review Board Statement: Not applicable.

Informed Consent Statement: Not applicable.

Data Availability Statement: Not applicable.

Conflicts of Interest: The authors declare no conflict of interest.

\section{References}

1. Xu, Z.-D.; Shen, Y.-P.; Guo, Y.-Q. Semi-active control of structures incorporated with magnetorheological dampers using neural networks. Smart Mater. Struct. 2003, 12, 80-87. [CrossRef]

2. Xu, Z.-D.; Liao, Y.X.; Ge, T.; Xu, C. Experimental and Theoretical Study of Viscoelastic Dampers with Different Matrix Rubbers. J. Eng. Mech. 2016, 142, 04016051. [CrossRef]

3. Lu, H.; Xu, Z.-D.; Azimi, M.; Fu, L.; Wang, Y. An Effective Data-Driven Model for Predicting Energy Consumption of LongDistance Oil Pipelines. J. Pipeline Syst. Eng. Pract. 2022, 13, 04022005. [CrossRef]

4. Lu, H.; Iseley, T.; Matthews, J.; Liao, W. Hybrid machine learning for pullback force forecasting during horizontal directional drilling. Autom. Constr. 2021, 129, 103810. [CrossRef]

5. Xu, Z.-D.; Jia, D.-H.; Zhang, X.-C. Performance tests and mathematical model considering magnetic saturation for magnetorheological damper. J. Intell. Mater. Syst. Struct. 2012, 23, 1331-1349. [CrossRef]

6. GB/T 20801; Pressure Piping Code Industrial Piping Part 1: General. China Standardization Committee on Boilers and Pressure Vessels: Beijing, China, 2006.

7. Chilton, E.G.; Handley, L. Pulsations in gas compressor systems. Trans. ASME 1952, 45, 214-218.

8. Sun, S.Y.; Ren, T.R.; Shi, Y.M.; Cui, T.S. Optimum disposition of assembled piping system for parallel operation of multiple compressors. Int. J. Press. Vessel. Pip. 1996, 68, 145-151.

9. Attenuation of Gas Pulsations Using A Perforated Tube. Available online: https://docs.lib.purdue.edu/icec/237 (accessed on 20 December 2021).

10. Shin, Y.W.; Wiedermann, A.H. A Method for Suppression of Pressure Pulses in Fluid-Filled Piping-Part I: Theoretical Analysis. J. Press. Vessel Technol. 1992, 114, 60-65. [CrossRef]

11. Shin, Y.W.; Bielick, E.F.; Wiedermann, A.H.; Ockert, C.E. A Method for Suppression of Pressure Pulse in Fluid-Filled Piping-Part II: Experimental Verification. J. Press. Vessel Technol. 1992, 114, 66-73. [CrossRef]

12. Chen, L.L.; Xie, Z.N. A research for the optimization of the vibrating excitation in reciprocating compressor piping system. Chin. J. Appl. Mech. 1995, 12, 102-105.

13. Chen, L.L.; Wang, R.; Xu, J.X. A study on the dynamic optimum of the supported stiffness for piping structure in reciprocating compressor systems. J. Xi'an Jiaotong Univ. 1996, 30, 95-100.

14. Cheng, M.G. Vibration analysis and vibration reduction for inlet of water filling pump. Petro-Chem. Equip. Technol. 1995, 16, 51-52.

15. Xing, K.L.; Ge, S.H.; Ding, C.S.; He, R. Theoretical analysis of a new serial pocket-type accumulator. Constr. Machin. Equip. 1997, $28,24-26$.

16. Zhang, H.J. Vibration analysis and modification measures for piping of reciprocating pump. Chem. Eng. Design 2000, $10,12-15$.

17. Xie, P.A.; Wang, Q. Study on attenuation of fluid-borne pulsation using accumulator. Noise Vib. Control 2000, 4, 2-5.

18. Wang, Q.; Shen, R.Y.; Yao, B.Y.; Ding, W. Attenuation of vibration and pulsating pressure of pipeline using pipe attenuator. Shipbuild. China 2003, 44, 39-45.

19. Xue, W.F. The Study on Vibration and Vibration Control of the Pipeline of Reciprocating Compressor. Master's Thesis, Fuzhou University, Fujian, China, 2003. 
20. Xiao, G.M. The Research on Vibration Control of the Pipeline of Piston Compressor. Master's Thesis, Southwest Jiaotong University, Chengdu, China, 2006.

21. Yu, C.L.; Wei, Y.; Hu, X.M. Piping vibration analysis for the type of reciprocating compressor. China Offshore Platf. 2007, 22, 52-56.

22. Chen, H.F. Study on Vibration Characteristics and Safety Evaluation of Reciprocating Compressor Pipeline. Master's Thesis, China University of Petroleum, Qingdao, China, 2009.

23. Sui, K.; Wang, J. Calculation and analysis on residential pipeline pressure pulsation. Environ. Technol. 2013, z1, 203-206.

24. Lu, H.; Huang, K.; Wu, S. Vibration and Stress Analyses of Positive Displacement Pump Pipeline Systems in Oil Transportation Stations. J. Pipeline Syst. Eng. Pract. 2016, 7, 05015002. [CrossRef]

25. Su, P.; Liu, Y.H.; Wang, Z.Y.; Wang, Y.B. Finite element numerical simulation on thermal stress distribution of LNG pipeline. Contemp. Chem. Industry 2013, 42, 1198-1200.

26. Liu, H.F.; Xu, H.Z. The LNG pipe stress calculation and analysis. Chem. Ind. Times 2013, 27, $21-22$.

27. Yu, G.P.; Zhao, G.M.; Zhang, Y.X. Stress analysis of low temperature pipeline in LNG tank area. Petro-Chem. Design 2015, 32, $22-25$.

28. Xu, Q.; Liu, C.; Wang, X.; Cao, Y.; Yu, H.; Li, W.; Guo, L. Machine learning classification of flow regimes in a long pipeline-riser system with differential pressure signal. Chem. Eng. Sci. 2021, 233, 116402. [CrossRef]

29. Xu, Q.; Liang, L.; She, Y.; Xie, X.; Guo, L. Numerical investigation on thermal hydraulic characteristics of steam jet condensation in subcooled water flow in pipes. Int. J. Heat Mass Transf. 2022, 184, 122277. [CrossRef]

30. Hwang, S.-Y.; Kim, M.-S.; Lee, J.-H. Thermal Stress Analysis of Process Piping System Installed on LNG Vessel Subject to Hull Design Loads. J. Mar. Sci. Eng. 2020, 8, 926. [CrossRef]

31. American Petroleum Institute. Reciprocating Compressors for Petroleum, Chemical, and Gas Industry Services; API 618; American Petroleum Institute: Washington, DC, USA, 2007.

32. Lu, H.; Wu, X.; Ni, H.; Azimi, M.; Yan, X.; Niu, Y. Stress analysis of urban gas pipeline repaired by inserted hose lining method. Compos. Part B Eng. 2020, 183, 107657. [CrossRef]

33. Xu, Z.-D.; Wang, D.-X.; Shi, C.-F. Model, tests and application design for viscoelastic dampers. J. Vib. Control 2011, 17, 1359-1370. [CrossRef]

34. Xu, Z.-D.; Yang, Y.; Miao, A.-N. Dynamic Analysis and Parameter Optimization of Pipelines with Multidimensional Vibration Isolation and Mitigation Device. J. Pipeline Syst. Eng. Pract. 2021, 12, 04020058. [CrossRef]

35. Xu, Z.-D.; Zhu, C.; Shao, L.-W. Damage Identification of Pipeline Based on Ultrasonic Guided Wave and Wavelet Denoising. J. Pipeline Syst. Eng. Pract. 2021, 12, 04021051. [CrossRef]

36. George, M. Pipe Stress Analysis Theory Guide; COADE Inc., China Technical Service and Training Center: Beijing, China, 1998.

37. ASME. Process Piping; B31.3; ASME: New York, NY, USA, 2013.

38. Song, K.K. Industrial Pipe Stress Analysis and Engineering Applications; Press of China Petrochemical: Beijing, China, 2011.

39. Xu, Z.-D.; Gai, P.-P.; Zhao, H.-Y.; Huang, X.-H.; Lu, L.-Y. Experimental and theoretical study on a building structure controlled by multi-dimensional earthquake isolation and mitigation devices. Nonlinear Dyn. 2017, 89, 723-740. [CrossRef]

40. Lu, H.; Xu, Z.-D.; Iseley, T.; Matthews, J.C. Novel Data-Driven Framework for Predicting Residual Strength of Corroded Pipelines. J. Pipeline Syst. Eng. Pract. 2021, 12, 04021045. [CrossRef]

41. Lu, H.; Iseley, T.; Matthews, J.; Liao, W.; Azimi, M. An ensemble model based on relevance vector machine and multi-objective salp swarm algorithm for predicting burst pressure of corroded pipelines. J. Pet. Sci. Eng. 2021, 203, 108585. [CrossRef]

42. Xu, Z.-D.; Xu, F.-H.; Chen, X. Vibration suppression on a platform by using vibration isolation and mitigation devices. Nonlinear Dyn. 2016, 83, 1341-1353. [CrossRef]

43. Lu, H.F. Stress and Vibration Analysis of Reciprocating Pump Piping Systems. Master's Thesis, Southwest Petroleum University, Chengdu, China, 2016. 